\title{
Mechanical properties of cotton fabric reinforced geopolymer composites at $200-1000{ }^{\circ} \mathrm{C}$
}

\author{
Thamer ALOMAYRI ${ }^{a, b}$, Les VICKERS ${ }^{a}$, Faiz U. A. SHAIKH ${ }^{c}$, It-Meng LOW ${ }^{a,{ }^{*}}$ \\ ${ }^{a}$ Department of Imaging \& Applied Physics, Curtin University, GPO Box U1987, Perth, WA 6845, Australia \\ ${ }^{b}$ Department of Physics, Umm Al-Qura University, Makkah 21955, Saudi Arabia \\ ${ }^{c}$ Department of Civil Engineering, Curtin University, GPO Box U1987, Perth, WA 6845, Australia
}

Received: April 09, 2014; Revised: May 15, 2014; Accepted: May 28, 2014

OThe Author(s) 2014. This article is published with open access at Springerlink.com

\begin{abstract}
Geopolymer composites containing woven cotton fabric $(0-8.3 \mathrm{wt} \%)$ were fabricated using the hand lay-up technique, and were exposed to elevated temperatures of $200{ }^{\circ} \mathrm{C}, 400{ }^{\circ} \mathrm{C}$, $600{ }^{\circ} \mathrm{C}, 800{ }^{\circ} \mathrm{C}$ and $1000{ }^{\circ} \mathrm{C}$. With an increase in temperature, the geopolymer composites exhibited a reduction in compressive strength, flexural strength and fracture toughness. When heated above $600{ }^{\circ} \mathrm{C}$, the composites exhibited a significant reduction in mechanical properties. They also exhibited brittle behavior due to severe degradation of cotton fibres and the creation of additional porosity in the composites. Microstructural images verified the existence of voids and small channels in the composites due to fibre degradation.
\end{abstract}

Keywords: geopolymer composites; microstructures; mechanical properties; fracture toughness

\section{Introduction}

Portland cements are used in many building and construction applications because of their good mechanical performance. However, the emission of greenhouse gases associated with their manufacture is a serious problem. In recent years, a new class of environmentally friendly and sustainable inorganic aluminosilicate polymers (known as geopolymers) has emerged as an alternative to Portland cements. These inorganic compounds do not use Portland cements as binder, but instead employ a material such as fly-ash, rich in silicon $(\mathrm{Si})$ and aluminium $(\mathrm{Al})$, which reacts to alkaline liquids to produce binder [1-4]. Geopolymers

\footnotetext{
* Corresponding author.

E-mail: j.low@curtin.edu.au
}

have attracted the interest of scientists due to their low cost, low curing and hardening temperatures, and excellent thermal stability at high temperatures [5-9]. However, despite these desirable attributes, they suffer from brittle failure like most ceramics. This limitation may be readily overcome through fibre reinforcement as in high-performance polymer-matrix composites. Hitherto, the most common fibre reinforcement used in geopolymer composites is based on steel, carbon, polypropylene (PP) and polyvinyl alcohol (PVA) [10-15].

Current concerns over the environment and climate change have given rise to an increasing interest in replacing the synthetic fibres currently used in geopolymer composites or other brittle matrices with natural plant fibres $[16,17]$. Investigations of natural fibres such as sisal, coconut, bamboo, jute, banana, coir and hemp fibres have revealed desirable effects on 
the mechanical and physical properties of brittle organic and inorganic matrices [18-27]. For example, the mechanical and thermal properties of geopolymer resin have been significantly improved as a result of natural wool fibre reinforcement [28,29]. Similarly, Teixeira-Pinto et al. [30] found that jute fibres are effective in improving the mechanical properties of geopolymer composites, and Al Bakri et al. [31] observed a similar desirable effect in wood-fibre reinforced geopolymers.

In recent years, investigations into the resistance of geopolymer concrete to elevated temperatures have been of particular interest, and many promising results have been obtained [32]. One of the requirements for safety when designing construction structures is the ability to resist elevated temperatures which can lead to spalling because of reduced permeability and increased brittleness. In high-performance concrete, fibres are often added to overcome the adverse effects of fire-induced spalling, as they melt or degrade at certain temperatures and form dehydration pathways for escaping water, preventing pore pressure build-up. However, the presence of porosity and small channels created by fibre melting or degrading may reduce the mechanical strength of the composites [33,34].

According to the literature, the effect of elevated temperature on the mechanical properties of cotton fabric reinforced geopolymer matrix composites has not yet been reported so far. In the present work, therefore, cotton fibre/geopolymer composites were prepared and then heated at different temperatures ranging from $200{ }^{\circ} \mathrm{C}$ to $1000{ }^{\circ} \mathrm{C}$. Mechanical properties such as flexural strength, compressive strength and fracture toughness were evaluated. Thermogravimetric analysis (TGA), optical microscopy and scanning electron microscopy (SEM) were used to investigate their thermal behavior, microstructure and failure mechanisms. Results suggest that this is a promising area of investigation, adding significantly to the body of literature on natural and green alternatives to concrete.

\section{Experimental}

\section{1 Preparation of geopolymer composites}

Cotton fabric (CF) of $30 \mathrm{~cm} \times 7.5 \mathrm{~cm}$ was used to reinforce the geopolymer composites. Low-calcium fly-ash (ASTM Class F), collected from Collie power station in Western Australia, was also used as the source material of the geopolymer matrix. The chemical composition of fly-ash (FA) is shown in Table 1. The alkaline activator for geopolymerisation was a combination of sodium hydroxide solution and sodium silicate grade D solution which were supplied by PQ Australia. Sodium hydroxide flakes with 98\% purity were used to prepare the solution. The chemical composition of sodium silicate used was $14.7 \% \mathrm{Na}_{2} \mathrm{O}$, $29.4 \% \mathrm{SiO}_{2}$ and $55.9 \%$ water by weight.

Composite samples were prepared by spreading a thin layer of geopolymer paste in a well-greased wooden mould, followed by carefully laying the first layer of woven cotton fabric on that layer. Thereafter, the fabric was fully impregnated (wet out) with geopolymer paste by a roller before placing the next layer. This process was repeated for the desired numbers of cotton fabric layers. Each specimen contained different layers of cotton fabric. For each specimen, the final layer was geopolymer paste. The alkaline solution to fly-ash weight ratio was fixed at 0.35 , whereas the weight ratio of sodium silicate solution to sodium hydroxide solution was maintained at 2.5. The composite specimens were placed on a vibration table in order to ensure better penetration of the matrix among the fabric openings and to remove the entrapped air voids. The specimens were also pressed under $25 \mathrm{~kg}$ load for $3 \mathrm{~h}$. Subsequently, the specimens were covered with plastic film and cured at $80{ }^{\circ} \mathrm{C}$ in an oven for $24 \mathrm{~h}$.

After curing, the composite samples with different weight percentages of fibres ( $0 \mathrm{wt} \%, 4.5 \mathrm{wt} \%, 6.2 \mathrm{wt} \%$ and $8.3 \mathrm{wt} \%$ ) were heated in a ventilated furnace to assess their strength retention at temperatures of $200{ }^{\circ} \mathrm{C}, 400{ }^{\circ} \mathrm{C}, 600{ }^{\circ} \mathrm{C}, 800{ }^{\circ} \mathrm{C}$ and $1000{ }^{\circ} \mathrm{C}$. The heating was carried out at a rate of $5{ }^{\circ} \mathrm{C} / \mathrm{min}$ until the target temperatures were reached; these final temperatures were held for $2 \mathrm{~h}$. The specimens were left to cool naturally inside the furnace before being removed to room temperature. Their dimensions were measured using a digital vernier calliper to determine drying shrinkage $(D)$ using the following equation:

$$
D=\frac{L_{0}-L}{L_{0}} \times 100 \%
$$

where $L_{0}$ is the initial length of specimens before

Table 1 Chemical composition of fly-ash in

weight percentage (Unit: wt\%)

\begin{tabular}{llllllllll}
\hline $\mathrm{SiO}_{2}$ & $\mathrm{Al}_{2} \mathrm{O}_{3}$ & $\mathrm{Fe}_{2} \mathrm{O}_{3}$ & $\mathrm{CaO}$ & $\mathrm{MgO}$ & $\mathrm{SO}_{3}$ & $\mathrm{Na}_{2} \mathrm{O}$ & $\mathrm{K}_{2} \mathrm{O}$ & Others & LOI
\end{tabular}

\begin{tabular}{cccccccccc}
50 & 28.25 & 13.5 & 1.78 & 0.89 & 0.38 & 0.32 & 0.46 & 2.78 & 1.64 \\
\hline
\end{tabular}


heating; and $L$ is the length of specimens after heating.

\section{2 Characterisation}

\section{2. 1 Thermogravimetric analysis}

Thermogravimetric analysis (TGA) was carried out for cotton fibres, unreinforced geopolymer and cotton fabric reinforced geopolymer composites at a heating rate of $10{ }^{\circ} \mathrm{C} / \mathrm{min}$ under atmospheric condition. The temperature range scanned between $50{ }^{\circ} \mathrm{C}$ and $1000{ }^{\circ} \mathrm{C}$. The weight of all specimens was maintained around $15 \mathrm{mg}$.

\section{2. 2 Porosity}

Porosity tests were performed according to ASTM C20 [35]; the value of apparent porosity $\left(P_{\mathrm{s}}\right)$ was calculated using the following equation [35]:

$$
P_{\mathrm{s}}=\frac{W_{\mathrm{a}}-W_{\mathrm{d}}}{W_{\mathrm{a}}-W_{\mathrm{w}}} \times 100 \%
$$

where $W_{\mathrm{d}}$ is the weight of the dried sample; $W_{\mathrm{w}}$ is the weight of the sample saturated with and suspended in water; and $W_{\mathrm{a}}$ is the weight of the sample in air.

\section{2. 3 Optical microscopy and scanning electron microscopy}

The microstructures of the samples were studied under a Nikon SMZ 800 stereo microscope. This was undertaken to take advantage of the color contrast provided by optical microscopy.

A NEON 40EsB (Zeiss, Germany) field-emission SEM was used to examine the microstructures of the prepared samples. The fracture samples were mounted on aluminium stubs using carbon tape and coated with a thin layer of platinum to prevent charging during the observation.

\section{3 Mechanical properties}

Rectangular bars measuring $60 \mathrm{~mm} \times 20 \mathrm{~mm} \times 20 \mathrm{~mm}$ were cut from the fully cured samples and subjected to three-point bend tests performed in a LLOYD material testing machine ( $50 \mathrm{kN}$ capacity) with a displacement rate of $0.5 \mathrm{~mm} / \mathrm{min}$. Five specimens of each composition were tested. The flexural strength $\left(\sigma_{\mathrm{f}}\right)$ was determined using the following equation [9]:

$$
\sigma_{\mathrm{f}}=\frac{3}{2} \frac{p_{\max } S}{B W^{2}}
$$

where $p_{\max }$ is the maximum load at crack extension; $S$ is the span of the sample; $B$ is the specimen width; and $W$ is the specimen thickness (depth).

The compressive strength of the composites was measured using LLOYD material testing machine (50 $\mathrm{kN}$ capacity). The cubes were tested according to ASTM C109 [36]. The compressive strength $(C)$ was calculated using the following formula:

$$
C=\frac{p}{A}
$$

where $p$ is the total load on the sample at failure; $A$ is calculated area of the loaded surface of the specimen.

Rectangular bars of $60 \mathrm{~mm}$ long and a crosssectional dimension of $20 \mathrm{~mm} \times 20 \mathrm{~mm}$ were used in the fracture toughness measurements. A crack with a length to thickness (depth) ratio $(a / W)$ of 0.4 was introduced into each specimen using a $0.4 \mathrm{~mm}$ diamond blade, and the fracture toughness $K_{\text {IC }}$ was calculated using the following equation:

$$
K_{\mathrm{IC}}=\frac{p_{\max } S}{B W^{3 / 2}} f(a / W)
$$

where $p_{\max }$ is the maximum load at crack extension; $S$ is the span of the sample; $B$ is the specimen width; $W$ is the specimen thickness (depth); $a$ is the crack length; and $f(a / W)$ is the polynomial geometrical correction factor given by [17]:

$$
\begin{aligned}
& f(a / W)=\frac{3(a / W)^{1 / 2}}{2(1+2 a / W)(1-a / W)^{3 / 2}} \\
& \quad \times\left[1.99-(a / W)(1-a / W)\left(2.15-3.93 a / W+2.7 a^{2} / W^{2}\right)\right]
\end{aligned}
$$

\section{Results and discussion}

\section{1 Thermal properties}

The thermal stability of the composites was studied using the thermogravimetric analysis (TGA); thermograms of pure geopolymers, geopolymer composites and cotton fibres are shown in Fig. 1. The geopolymer matrix undergoes weight loss between $50{ }^{\circ} \mathrm{C}$ and $250{ }^{\circ} \mathrm{C}$ due to the evaporation of free water. The composites show a similar trend, with a slight additional weight loss above $250{ }^{\circ} \mathrm{C}$ which may be attributed to the thermal decomposition of the cotton fibres. 


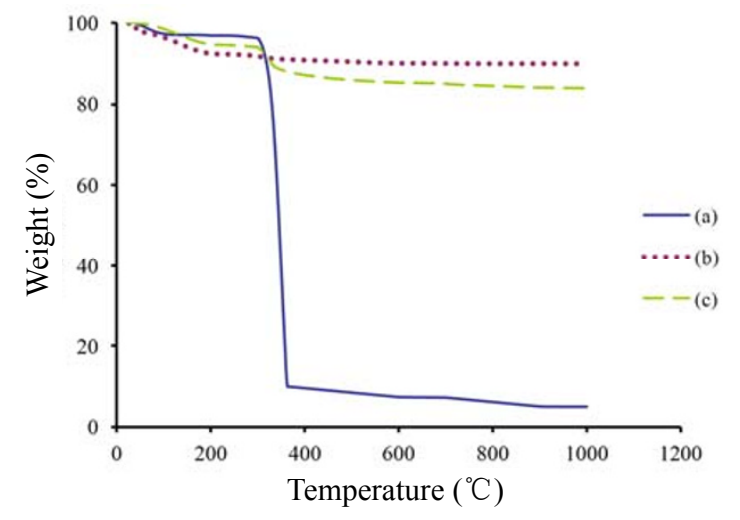

Fig. 1 TGA curves of (a) cotton fibres, (b) pure geopolymers and (c) geopolymer composites.

As shown in Fig. 1, pure cotton fibres degrade in three main stages. The first transition occurs from 50 ${ }^{\circ} \mathrm{C}$ to about $250{ }^{\circ} \mathrm{C}$, with the release of absorbed moisture from the fibre by evaporation. In this stage, the weight loss of cotton fibres is roughly similar to that of other natural fibres such as kenaf, jute and wood [37-39]. The second transition occurs between $250{ }^{\circ} \mathrm{C}$ and $370{ }^{\circ} \mathrm{C}$ when a large weight loss occurs, attributable to the degradation of cellulose. The third stage occurs above $370{ }^{\circ} \mathrm{C}$ when the fibres start to decompose, but shows a lower rate of weight loss. In this stage, all volatile materials are driven off, resulting in the formation of residual char in the sample. Similar degradation stages of cotton fibres were observed by Babu et al. [40] when they studied the thermal decomposition characteristics of cotton fibres using the thermogravimetric analysis.

\section{2 Temperature effects on drying shrinkage}

Figure 2 shows that the shrinkage of geopolymer composites increases with an increase of cotton fibres in the matrix. This tendency is observed for all samples at various temperatures. In all the three composites

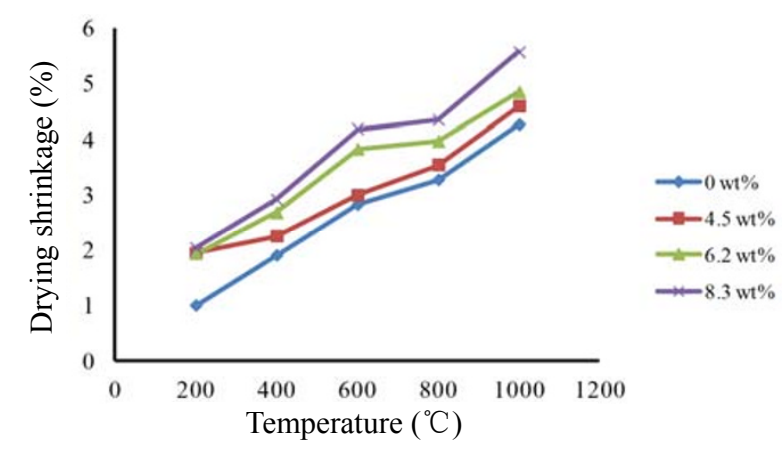

Fig. 2 Drying shrinkage of geopolymer composites at various temperatures. containing cotton fibres $(4.5 \mathrm{wt} \%, \quad 6.2 \mathrm{wt} \%$ and $8.2 \mathrm{wt} \%)$, the drying shrinkage increases as temperature increases.

This is in contrast with reports of reduced shrinkage in geopolymer composites containing a small quantity of synthetic fibres such as carbon at elevated temperatures [41]. Shrinkage of geopolymer composites is influenced by many factors, including fibre type and fibre content when drying begins. The results here indicate that the addition of cotton fibres increases the matrix porosity (Fig. 3) and contributes to a higher drying shrinkage. This is due to more moisture paths being created into the matrix, which is also reported by Toledo Filho et al. [42] in their study of the effect of vegetable fibres on drying shrinkage of cement mortar composites.

\section{3 Change in color with temperature}

After heating at various temperatures, the samples were assessed visually to determine the color change. Photographs of the geopolymer composite samples before and after heating at various temperatures are shown in Fig. 4.

All samples exhibit a change in color after exposure to elevated temperatures as follows: grey at $200{ }^{\circ} \mathrm{C}$,

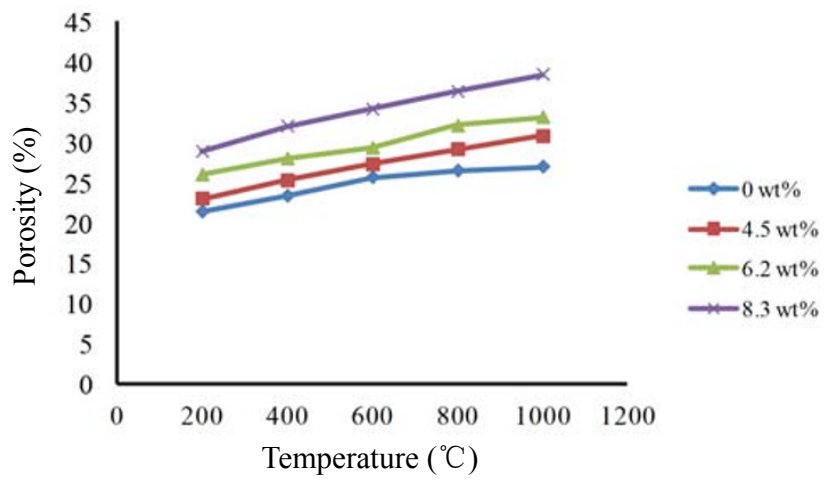

Fig. 3 Porosity of geopolymer composites at various temperatures.

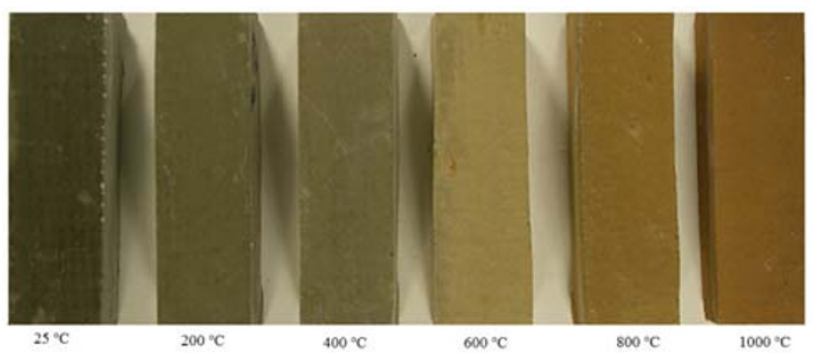

Fig. 4 Geopolymer composites loaded with $8.3 \mathrm{wt} \% \mathrm{CF}$ before and after heating at various temperatures. 
yellowish grey between $400{ }^{\circ} \mathrm{C}$ and $600{ }^{\circ} \mathrm{C}$, pink up to $800{ }^{\circ} \mathrm{C}$, and reddish brown at $1000{ }^{\circ} \mathrm{C}$. High temperature exposure causes the oxidation and liberation of iron species present in the fly-ash particles, where similar observations were also reported by Rickard et al. [43] when testing the color change of Collie fly-ash geopolymers at elevated temperatures. Such color changes are a useful tool for estimating temperatures easily which have been reached after exposure to fire. They can also be used as an indication of significant loss in mechanical properties and are useful since the appearance coincides with a significant reduction in strength as a result of heating [44].

\section{4 Crack analysis}

It is well known that cracks occur in concrete during fire because of the internal pressure of evaporable moisture, characterised by hairline cracks over the surface at low to medium temperatures and extending deep into the specimen at higher temperatures. The result is a significant reduction in structural integrity and load-carrying capacity [45]. One of the primary mechanisms responsible for concrete cracking is low porosity, which slows the migration of water vapour and offers few escape channels, leading to higher pore pressures [46].

In this study, networks of hairline cracks are observed on un-reinforced geopolymer specimens heated at $400{ }^{\circ} \mathrm{C}$ and $600{ }^{\circ} \mathrm{C}$. Beyond $600{ }^{\circ} \mathrm{C}$, severe cracking occurs on the surfaces, as shown in Fig. 5. It is probable that cracking is initially due to the normal thermal contraction of geopolymer paste, causing local changes to the geopolymer microstructure. An increment in temperature leads to additional contraction in the matrix as water is driven off. This phenomenon has been observed to occur in the geopolymer gel during dehydroxylation between $300{ }^{\circ} \mathrm{C}$ and $600{ }^{\circ} \mathrm{C}$ [47]. However, when cotton fibres are incorporated, no crack is found in the surface of geopolymer composites as shown in Fig. 4. This indicates that cotton fibres are very effective in prevention of cracking caused by high temperatures due to the formation of small cavities inside the matrix created by the fibre degradation. The structure of the composites becomes more porous, and the expanded water vapour escapes without substantial damage to the microstructure.

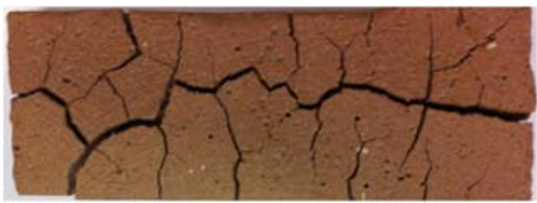

Fig. 5 Photograph of the geopolymer composites loaded with $0 \mathrm{wt} \% \mathrm{CF}$ after heating at $1000{ }^{\circ} \mathrm{C}$.

Such degradation of the cotton fibres may be beneficial to the behavior of geopolymer composites under thermal exposure. At high temperatures, when all water is not expelled fast enough from the composites, internal vaporisation may create high pressures inside the matrix. The porosity and small channels created by the degradation of the cotton fibres may lower internal vapour pressures and thus reduce the likelihood of cracking.

\section{5 Effects of temperature on mechanical properties}

\section{5.1 Compressive strength}

The influence of elevated temperature on compressive strength of geopolymer composites is exhibited in Fig. 6. The compressive strength of all geopolymer composites decreases after exposure to temperatures between $200{ }^{\circ} \mathrm{C}$ and $1000{ }^{\circ} \mathrm{C}$. This reduction in compressive strength is probably because of the persistent deterioration of the geopolymer hydrates, which contributes most of the compressive strength of the composites, as temperature increases. Moreover, this decreasing tendency in compressive strength also results from increasing porosity as temperature increases. The total porosities of the composites heated to $800{ }^{\circ} \mathrm{C}$ and $1000{ }^{\circ} \mathrm{C}$ are higher than those at $200{ }^{\circ} \mathrm{C}$, $400{ }^{\circ} \mathrm{C}$ and $600{ }^{\circ} \mathrm{C}$ (Fig. 3). The hydrophilic nature of cotton fibres enables the composites to take up moisture from the surrounding environment, increasing their water content. Upon heating, dehydration causes weight loss as is evident in Fig. 1. At low temperatures, dehydration is slow, but as temperature increases, so does the dehydration rate, leading to greater weight loss and the formation of a large quantity of voids that damage the bond between fibre and matrix and act as stress concentration points, resulting in a loss in load-bearing capacity [17]. Some authors carried out compressive tests on concrete containing polypropylene (PP) fibres and reported that, the strength properties decrease with the increase of temperature, due to the additional porosity and small 


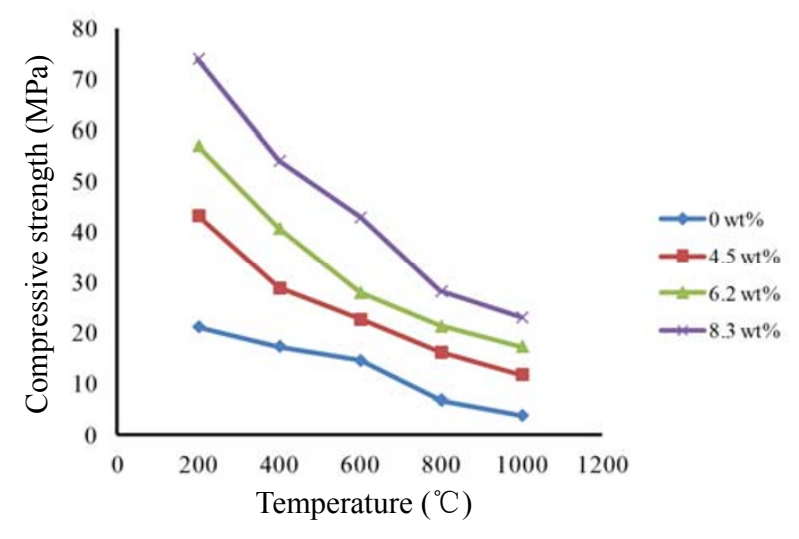

Fig. 6 Compressive strength of geopolymer composites at various temperatures.

channels created by the melting of the PP fibres [48-50].

\subsection{Flexural strength}

Like compressive strength, the flexural strength of all the composites decreases with an increase in temperature. As shown in Fig. 7, the reduction in flexural strength of the composites at $800{ }^{\circ} \mathrm{C}$ and $1000{ }^{\circ} \mathrm{C}$ is greater than those at $200{ }^{\circ} \mathrm{C}, 400{ }^{\circ} \mathrm{C}$ and $600{ }^{\circ} \mathrm{C}$. The main cause of this strength reduction may be attributed to fibre degradation, or to burning and void formation. When temperature increases, more fibres may degrade and more voids form, leading to a continual decrease in flexural strength. SEM examinations reveal some cotton fibres surviving inside the specimens heated between $200{ }^{\circ} \mathrm{C}$ and $600{ }^{\circ} \mathrm{C}$ (Figs. 8(a)-8(c)): the possible reason for the higher flexural strength of these composites than those heated at $800{ }^{\circ} \mathrm{C}$ and $1000{ }^{\circ} \mathrm{C}$ where most of fibres degrade (Figs. 8(d) and 8(e)).

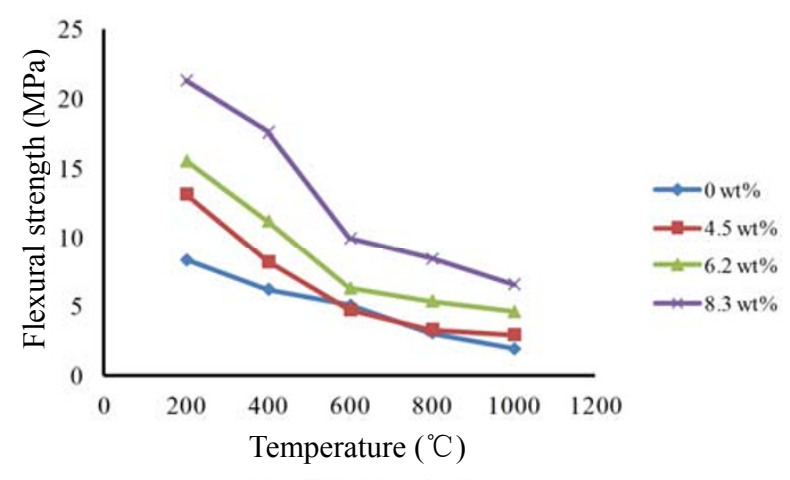

Fig. 7 Flexural strength of geopolymer composites at various temperatures.
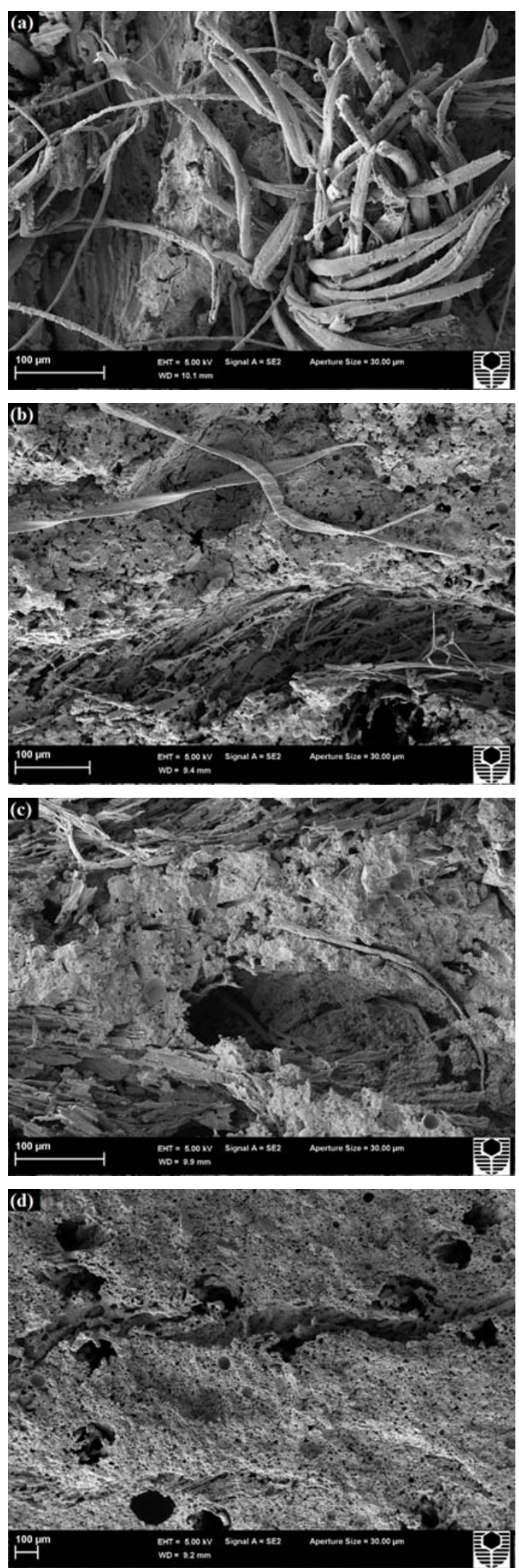


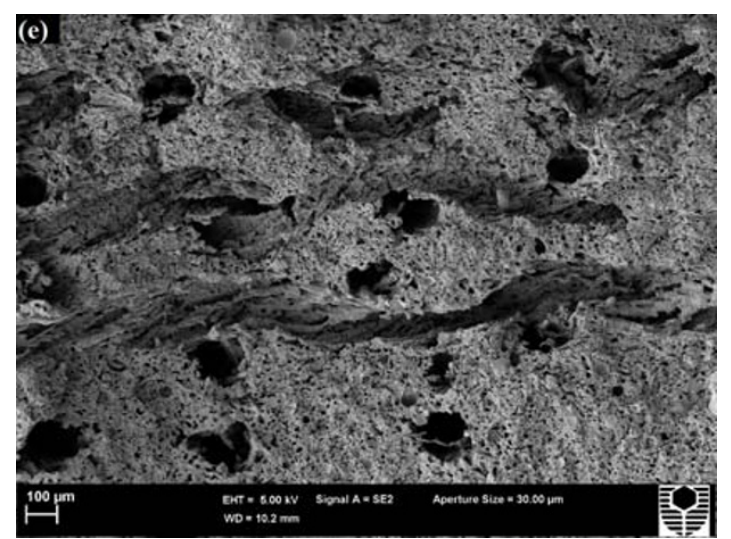

Fig. 8 SEM images of the fracture surface for geopolymer composites loaded with $8.3 \mathrm{wt} \% \mathrm{CF}$ at various temperatures: (a) $200{ }^{\circ} \mathrm{C}$, (b) $400{ }^{\circ} \mathrm{C}$, (c) $600{ }^{\circ} \mathrm{C}$, (d) $800{ }^{\circ} \mathrm{C}$ and (e) $1000{ }^{\circ} \mathrm{C}$.

Of the few reported investigations of the flexural strength of geopolymer composites at high temperatures, Lin et al.'s study [41] of elevated temperature on carbon fibre reinforced geopolymer composites found that flexural strength decreases with increasing temperature. They concluded that microcracking is the primary mechanism causing fibre degradation, occurring when high temperatures cause both free and hydration water to evaporate and leave voids, leading to lower flexural strength.

\section{5. 3 Fracture toughness}

In general, natural fibre-polymer composites display crack deflection, de-bonding between fibre and matrix, fibre pull-out and fibre-bridging, all of which contribute to improving fracture toughness $[51,52]$.

Figure 9 shows that an increase in temperature of the geopolymer composites causes a decrease in fracture toughness. This can be explained by the very high porosity caused by the oxidation and consequent degradation of the cotton fibres, becoming more severe

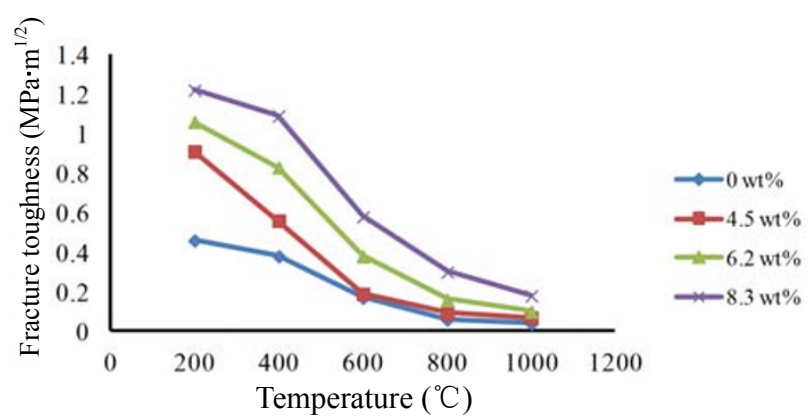

Fig. 9 Fracture toughness of geopolymer composites at various temperatures. as temperature increases. At the highest temperatures tested $\left(800{ }^{\circ} \mathrm{C}\right.$ and $\left.1000{ }^{\circ} \mathrm{C}\right)$, enhanced porosity formation in the matrices is observed, the probable result of the cotton fibre burning as shown in Figs. 8(d) and $8(\mathrm{e})$. The images show high porosity in the composites as consequence of cotton fibre degradation due to oxidation effects, thus resulting in low fracture toughness because no fibre pull-out or fibre-fracture is observed. At testing temperatures below $800{ }^{\circ} \mathrm{C}$, the higher fracture toughness of the composites may account for the presence of toughening mechanism such as fibre-bridging, fibre pull-out and fibre-fracture as only evident in the specimens exposed to 200-600 ${ }^{\circ} \mathrm{C}$ and confirmed by SEM observations (Figs. $8(a)-8(c))$.

\section{6 Microstructure analysis}

To observe changes in microstructure at moderate length scales, microscopy at low magnification and with a large field of view was conducted; Figs. 10(a)-10(c) show the optical micrographs of specimens exposed to elevated temperatures from $200{ }^{\circ} \mathrm{C}$ to $600{ }^{\circ} \mathrm{C}$. A significant amount of oxidation appears as dark "burns out" areas along the outer perimeter of the samples; but the centres remain pristine because oxygen is quickly depleted at the edge of the sample and no oxygen remains to react with the cotton fibres inside. The good condition of the interior fibres indicates that the geopolymer paste aids in stopping or significantly decreasing the supply of oxygen to the interior of the composites.

The matrix is effective in cutting off the oxygen supply to the fibres at temperature up to $600{ }^{\circ} \mathrm{C}$ (Figs. $10(\mathrm{a})-10(\mathrm{c}))$; however, as the specimen is heated further, many voids and caverns form around the edge and along the matrix (Figs. 10(d) and 10(e)), probably owing to the severe degradation of cotton fibres caused





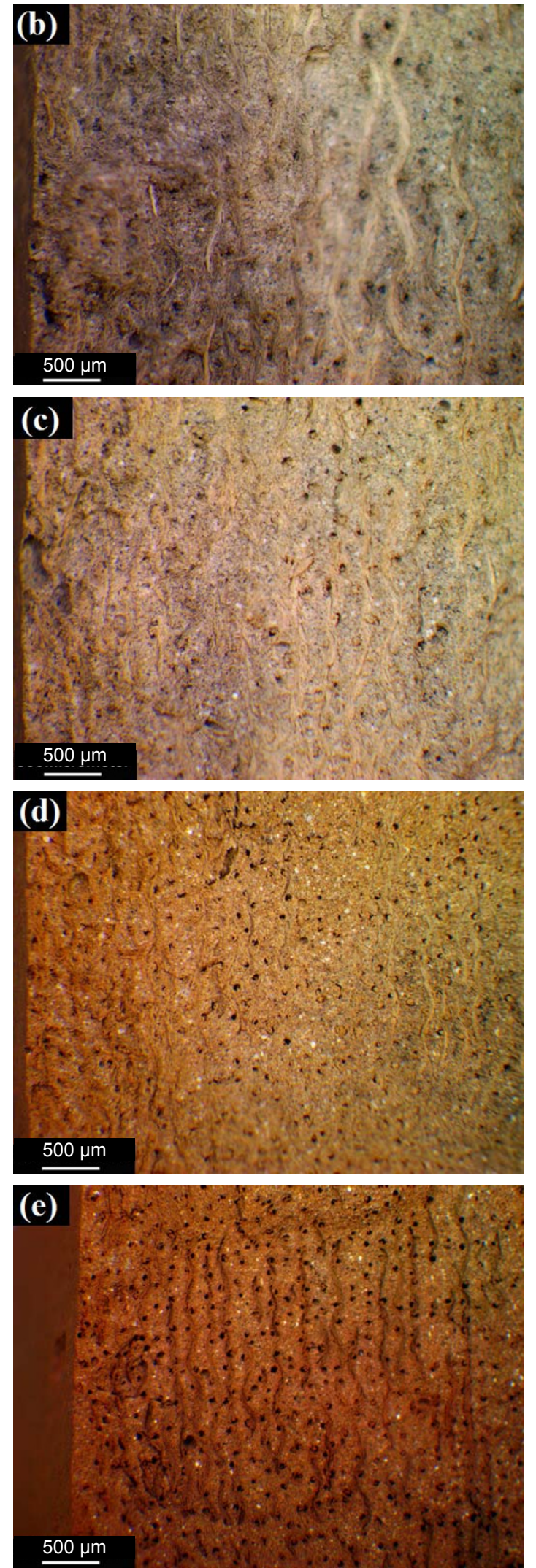

Fig. 10 Optical micrographs of geopolymer composites loaded with $8.3 \mathrm{wt} \% \mathrm{CF}$ at various temperatures: (a) $200{ }^{\circ} \mathrm{C}$, (b) $400{ }^{\circ} \mathrm{C}$, (c) $600{ }^{\circ} \mathrm{C}$, (d) $800{ }^{\circ} \mathrm{C}$ and (e) $1000{ }^{\circ} \mathrm{C}$. by oxidation along the edge and deep into the interior of the sample. As the temperature approaches $800{ }^{\circ} \mathrm{C}$ and $1000{ }^{\circ} \mathrm{C}$, oxygen is better able to diffuse into the interior and react with the fibres, leading to complete fibre burnout. However, no crack is observed in any of the specimens at these temperatures, possibly because the degrading cotton fibres form the dehydration pathways along which water could escape, preventing the build-up of pore pressures.

Therefore, the addition of cotton fibres to a geopolymer matrix has a positive influence, enhancing the temperature resistance and the mechanical and fracture properties of the composites. This makes them suitable for use in technological applications which are likely to be exposed to extreme high temperatures during wildfire: underground structures and reinforcement of mine works (adits, tunnels, etc.) are possibilities, as railroad and road tunnel constructions are.

\section{Conclusions}

The effect of temperature $\left(200-1000{ }^{\circ} \mathrm{C}\right)$ on the mechanical properties of cotton fabric reinforced geopolymer composites was investigated. Physical degradation mechanisms resulting from exposure to high temperatures were identified by monitoring color change, cracking and microstructure of the composites. The addition of cotton fibres has been shown to prevent matrix cracking after exposure of the geopolymer composites to high temperatures because of the additional porosity and small channels being created as they degrade.

The results also show that compressive strength, flexural strength and fracture toughness all decrease after exposure to high temperatures $\left(200-600{ }^{\circ} \mathrm{C}\right)$. A severe loss in strength was observed on specimens heated at $800{ }^{\circ} \mathrm{C}$ and $1000{ }^{\circ} \mathrm{C}$ due to fibre degradation and formation of a large quantity of voids.

\section{Acknowledgements}

The authors would like to thank Ms. E. Miller for the assistance with SEM.

Open Access: This article is distributed under the terms of the Creative Commons Attribution License which permits any use, distribution, and reproduction in any medium, provided the original author(s) and the source are credited. 


\section{References}

[1] Shaikh FUA. Deflection hardening behaviour of short fibre reinforced fly ash based geopolymer composites. Mater Design 2013, 50: 674-682.

[2] Shaikh FUA. Review of mechanical properties of short fibre reinforced geopolymer composites. Constr Build Mater 2013, 43: 37-49.

[3] Davidovits J. Geopolymers. J Therm Anal 1991, 37: 1633-1656.

[4] Pernica D, Reis PNB, Ferreira JAM, et al. Effect of test conditions on the bending strength of a geopolymer-reinforced composite. J Mater Sci 2010, 45: 744-749.

[5] Barbosa VFF, MacKenzie KJD. Synthesis and thermal behaviour of potassium sialate geopolymers. Mater Lett 2003, 57: 1477-1482.

[6] Rickard WDA, Temuujin J, van Riessen A. Thermal analysis of geopolymer pastes synthesised from five fly ashes of variable composition. J Non-Cryst Solids 2012, 358: 1830-1839.

[7] Rickard WDA, Williams R, Temuujin J, et al. Assessing the suitability of three Australian fly ashes as an aluminosilicate source for geopolymers in high temperature applications. Mat Sci Eng A 2011, 528: 3390-3397.

[8] Tchakoute HK, Elimbi A, Yanne E, et al. Utilization of volcanic ashes for the production of geopolymers cured at ambient temperature. Cement Concrete Comp 2013, 38: 75-81.

[9] Zhao Q, Nair B, Rahimian T, et al. Novel geopolymer based composites with enhanced ductility. J Mater Sci 2007, 42: 3131-3137.

[10] Bernal S, De Gutierrez R, Delvasto S, et al. Performance of an alkali-activated slag concrete reinforced with steel fibers. Constr Build Mater 2010, 24: $208-214$

[11] Katakalos K, Papakonstantinou C. Fatigue of reinforced concrete beams strengthened with steel-reinforced inorganic polymers. $J$ Compos Constr 2009, 13: 103-112.

[12] Vaidya S, Allouche EN. Strain sensing of carbon fiber reinforced geopolymer concrete. Mater Struct 2011, 44: 1467-1475.

[13] Zhang Z, Yao X, Zhu H, et al. Preparation and mechanical properties of polypropylene fiber reinforced calcined kaolin-fly ash based geopolymer. J Cent South Univ T 2009, 16: 49-52.

[14] Zhang Y, Sun W, Li Z. Impact behavior and microstructural characteristics of PVA fiber reinforced fly ash-geopolymer boards prepared by extrusion technique. J Mater Sci 2006, 41:
2787-2794.

[15] Zhang Y, Sun W, Li Z, et al. Impact properties of geopolymer based extrudates incorporated with fly ash and PVA short fiber. Constr Build Mater 2008, 22: 370-383.

[16] Dhakal HN, Zhang ZY, Richardson MOW. Effect of water absorption on the mechanical properties of hemp fibre reinforced unsaturated polyester composites. Compos Sci Technol 2007, 67: 1674-1683.

[17] Low IM, McGrath M, Lawrence D, et al. Mechanical and fracture properties of cellulose-fibre-reinforced epoxy laminates. Composites Part A 2007, 38: 963-974.

[18] Ramakrishna G, Sundararajan T. Impact strength of a few natural fibre reinforced cement mortar slabs: A comparative study. Cement Concrete Comp 2005, 27: 547-553.

[19] Reis JML. Fracture and flexural characterization of natural fiber-reinforced polymer concrete. Constr Build Mater 2006, 20: 673-678.

[20] Mansur MA, Aziz MA. Study of bamboo-mesh reinforced cement composites. International Journal of Cement Composites and Lightweight Concrete 1983, 5: 165-171.

[21] Mansur MA, Aziz MA. A study of jute fibre reinforced cement composites. International Journal of Cement Composites and Lightweight Concrete 1982, 4: 75-82.

[22] Chakraborty S, Kundu SP, Roy A, et al. Improvement of the mechanical properties of jute fibre reinforced cement mortar: A statistical approach. Constr Build Mater 2013, 38: 776-784.

[23] Savastano Jr H, Warden PG, Coutts RSP. Microstructure and mechanical properties of waste fibre-cement composites. Cement Concrete Comp 2005, 27: 583-592.

[24] Ali M, Liu A, Sou H, et al. Mechanical and dynamic properties of coconut fibre reinforced concrete. Constr Build Mater 2012, 30: 814-825.

[25] Yan L, Chouw N. Experimental study of flax FRP tube encased coir fibre reinforced concrete composite column. Constr Build Mater 2013, 40: 1118-1127.

[26] Sedan D, Pagnoux C, Smith A, et al. Mechanical properties of hemp fibre reinforced cement: Influence of the fibre/matrix interaction. $J$ Eur Ceram Soc 2008, 28: 183-192.

[27] Hakamy A, Shaikh FUA, Low IM. Microstructures and mechanical properties of hemp fabric reinforced organoclay-cement nanocomposites. Constr Build Mater 2013, 49: 298-307.

[28] Alzeer M, MacKenzie KJD. Synthesis and 
mechanical properties of new fibre-reinforced composites of inorganic polymers with natural wool fibres. J Mater Sci 2012, 47: 6958-6965.

[29] Alzeer M, MacKenzie K. Synthesis and mechanical properties of novel composites of inorganic polymers (geopolymers) with unidirectional natural flax fibres (phormium tenax). Appl Clay Sci 2013, 75-76: 148-152.

[30] Teixeira-Pinto A, Varela B, Shrotri K, et al. Geopolymer-jute composite: A novel environmentally friendly composite with fire resistant properties. Developments in Porous, Biological and Geopolymer Ceramics: Ceramic Engineering and Science Proceedings 2009, 28: 337-346.

[31] Al Bakri AMM, Izzat AM, Faheem MTM, et al. Feasibility of producing wood fibre-reinforced geopolymer composites (WFRGC). Adv Mat Res 2013, 626: 918-925.

[32] Cheng TW, Chiu JP. Fire-resistant geopolymer produced by granulated blast furnace slag. Miner Eng 2003, 16: 205-210.

[33] Kalifa P, Chéné G, Gallé C. High-temperature behaviour of HPC with polypropylene fibers: From spalling to microstructure. Cement Concrete Res 2001, 31: 1487-1499.

[34] Xiao J, Falkner H. On residual strength of high-performance concrete with and without polypropylene fibres at elevated temperatures. Fire Safety J 2006, 41: 115-121.

[35] ASTM International. ASTM C20-00 Standard test methods for apparent porosity, water absorption, apparent specific gravity, and bulk density of burned refractory brick and shapes by boiling water. 2010 .

[36] ASTM International. ASTM C109/C109M-12 Standard test method for compressive strength of hydraulic cement mortars (using 2-in. or [50-mm] cube specimens). 2013.

[37] Julkapli NM, Akil HM. Thermal properties of kenaf-filled chitosan biocomposites. Polym-Plast Technol 2010, 49: 147-153.

[38] Ray D, Sarkar BK, Basak RK, et al. Study of the thermal behavior of alkali-treated jute fibres. $J \mathrm{Appl}$ Polym Sci 2002, 85: 2594-2599.

[39] Huda MS, Drzal LT, Misra M, et al. Wood-fiber-reinforced poly(lactic acid) composites: Evaluation of the physicomechanical and morphological properties. J Appl Polym Sci 2006, 102: 4856-4869.

[40] Babu KF, Senthilkumar R, Noel M, et al. Polypyrrole microstructure deposited by chemical and electrochemical methods on cotton fabrics. Synthetic Met 2009, 159: 1353-1358.
[41] Lin T, Jia D, He P, et al. Thermal-mechanical properties of short carbon fiber reinforced geopolymer matrix composites subjected to thermal load. J Cent South Univ T 2009, 16: 881-886.

[42] Toledo Filho RD, Ghavami K, Sanjuán M, et al. Free, restrained and drying shrinkage of cement mortar composites reinforced with vegetable fibres. Cement Concrete Comp 2005, 27: 537-546.

[43] Rickard WDA, van Riessen A, Walls P. Thermal character of geopolymers synthesized from class $\mathrm{F}$ fly ash containing high concentrations of iron and

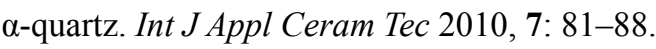

[44] Short NR, Purkiss JA, Guise SE. Assessment of fire damaged concrete using colour image analysis. Constr Build Mater 2001, 15: 9-15.

[45] Şahmaran M, Özbay E, Yücel H, et al. Effect of fly ash and PVA fiber on microstructural damage and residual properties of engineered cementitious composites exposed to high temperatures. $J$ Mater Civ Eng 2011, 23: 1735-1745.

[46] Khaliq W, Kodur V. Thermal and mechanical properties of fiber reinforced high performance self-consolidating concrete at elevated temperatures. Cement Concrete Res 2011, 41: 1112-1122.

[47] Duxson P, Lukey GC, van Deventer JSJ. Physical evolution of Na-geopolymer derived from metakaolin up to $1000{ }^{\circ} \mathrm{C}$. J Mater Sci 2007, 42: 3044-3054.

[48] Noumowe A. Mechanical properties and microstructure of high strength concrete containing polypropylene fibres exposed to temperatures up to $200{ }^{\circ} \mathrm{C}$. Cement Concrete Res 2005, 35: 2192-2198.

[49] Uysal M, Tanyildizi H. Estimation of compressive strength of self compacting concrete containing polypropylene fiber and mineral additives exposed to high temperature using artificial neural network. Constr Build Mater 2012, 27: 404-414.

[50] Behnood A, Ghandehari M. Comparison of compressive and splitting tensile strength of high-strength concrete with and without polypropylene fibers heated to high temperatures. Fire Safety J 2009, 44: 1015-1022.

[51] Alamri H, Low IM. Microstructural, mechanical, and thermal characteristics of recycled cellulose fiber-halloysite-epoxy hybrid nanocomposites. Polym Composite 2012, 33: 589-600.

[52] Alhuthali A, Low IM, Dong C. Characterisation of the water absorption, mechanical and thermal properties of recycled cellulose fibre reinforced vinyl-ester eco-nanocomposites. Composites Part B 2012, 43: 2772-2781. 